\title{
Introduction to the Service Science Minitrack
}

\author{
Fu-ren Lin \\ Institute of Service Science \\ National Tsing Hua University \\ frlin@mx.nthu.edu.tw
}

\author{
Paul P. Maglio \\ School of Engineering \\ University of California, Merced \\ pmaglio@ucmerced.edu
}

\author{
Michael J. Shaw \\ Dept of Business Administration \\ University of Illinois, Urbana-Champaign \\ mjshaw@uiuc.edu
}

Now in its tenth year, the Service Science Minitrack at HICSS continues to bring together researchers and practitioners working in service science, the interdisciplinary study of service that combines perspectives from science, management, engineering, and design to innovate in service and service systems. Service science has had a global impact, with hundreds of universities worldwide offering courses, programs, or degrees related to service science, and with dozens of academic research institutes and groups established. This minitrack remains a platform for researchers and practitioners to share work, exchange ideas, and present results from this emerging discipline.

Service science deals with the design, development, and managerial issues of service systems, which we define as integrated, value-creating configurations of service providers, their clients, their partners, and others. The best-performing service systems are ITenabled, customer-centered, relationship-focused, and knowledge-intensive - yet span multiple formal and informal organizations. Because of this multidisciplinary context, researchers and practitioners in management, social sciences, and computer science are all working to increase service innovation. These multiple perspectives can be unified using the theoretical construct of the service system, in which entities (people, businesses, government agencies, etc.) interact to co-create value via value propositions that describe dynamic re-configurations of resources. The framework of value creation in complex service systems, which requires elaborating various stakeholder perspectives and understanding the broad context of use for specific cases to enable effective value creation especially given advanced and autonomous technology, is a central unifying framework across many papers and presentations in the Service Science Minitrack over the years.

The trend of increasing contributions to economic outputs from services-related activities in major countries means that service innovation is a major part of most business models today. Even in traditionally manufacturing-driven industries, such as IT and related industries, the importance of service has surpassed most other corporate competencies. From the outset, efforts in creating, composing, and delivering services call for systematic studies of managerial, technical, and social issues. Combining managerial, organizational, and technical perspectives, service science research and education aims to create service professionals with technological, business, and social-organizational abilities.

At HICSS 50 (2017), the Service Science Minitrack includes papers that connect rigorous disciplinary research with the emerging interdisciplinary framework of value creation in complex service systems, focusing on service design, with submissions from a variety of disciplines and a variety of participating communities that address issues in service policies, service process modeling, service delivery management, innovative service technologies, and the role of the Internet, the digital economy, and information technology, among others. 